\title{
Integrated Reform of Electronic Technology Courses in Higher Vocational Colleges Based on the OBE Concept
}

\author{
Jian Pan*, Li Wen, Lihua Qi, Dongqiu Xing, Yuting Zhao \\ School of Information and Communication, National University of Defense Technology, Xi'an 710106, Shaanxi Province, \\ China \\ *Corresponding author: Jian Pan, pan_jian_xian@163.com

\begin{abstract}
The education model based on outcomes-based education (OBE) emphasizes on taking educational achievements as the guide as well as focusing on student-centered and ability-based concepts. OBE is consistent with the talent output goals of higher vocational and technical education. Using the construction of electronic technology courses in higher vocational and technical colleges as an example, this article takes the course reform as an important carrier to promote ability training and explores the course reform scheme to meet the ability needs of higher vocational talents in the new era based on the concept of $\mathrm{OBE}$ in order to provide a useful reference for improving the level of talent training in higher vocational colleges.
\end{abstract}

Keywords: OBE; Higher vocational education; Electronic technology course; Teaching reform

Publication date: September 2021; Online publication: September 30, 2021

\section{Introduction}

OBE engineering education model emphasizes the core concepts of student-centered, output-oriented, and continuous improvement. Compared with the traditional education model, OBE engineering education model emphasizes more on the results of education. The main criterion for judging the quality of education is the practical abilities that students obtain from their education and how these abilities can help students in their career development and social survival ${ }^{[1]}$. As China has become a signatory member of the Washington Accord, its engineering talent education has embarked on a standardized and international route. The extensive focus of attention by colleges and universities is on how to use the concept and teaching mode of OBE as references to promote education reform and improve the quality of talent training.

In recent years, the state has advocated the development of vocational and technical education. As an important part of China's national education system, vocational and technical education undertakes the important function of cultivating applied and skilled talents for frontline production, construction, management, and services. Therefore, starting from the demand for talents, by closely following the industrial and technological development, focusing on the ability and quality needs of vocational posts for students, further positioning the core of education on vocational competence, and promoting the innovative development of higher vocational education, the education provided by higher vocational colleges would coincide with the OBE output-oriented education concept ${ }^{[2,3]}$.

In this article, the construction of the electronic technology course, which is a compulsory course for electronic information majors in higher vocational colleges, is used as an example. Based on the concept of $\mathrm{OBE}$, the course reform is taken as an important carrier to promote ability training, the needs of career development and talent's skills are considered as the traction and the goal, respectively, and the course 
reform scheme is explored to meet the ability needs of professional talents in the new era in order to improve the level of construction of professional basic courses in higher vocational colleges and provide support to enhance students' professional learning ability and competitiveness.

\section{Current teaching situation of electronic technology courses in higher vocational colleges}

As a main compulsory course of electronic information specialty in higher vocational education, the electronic technology course plays an important role to connect general basic courses and professional courses in the talent training system, leading students to step into the professional field in addition to consolidating the professional basic ability of talents. In recent years, many well-known universities at home and abroad have implemented task-based and project-based teaching models in electronic technology courses ${ }^{[4]}$. The advantages of these practices include clear teaching objectives, relatively flexible forms of teaching, and the teachings are designed around the completion of specific tasks or projects. In this way, teachings can better adopt the integration of theory and practice while further expanding the teaching space with the combination of online and offline resources.

However, at present, there are still several issues in the teaching of electronic technology courses at local higher vocational colleges. First, the teaching content largely focuses on basic contents, which are not closely linked to the follow-up professional courses. In addition, students feel that the goal of learning is unclear. Second, there is still a disconnection between theoretical teaching and practical teaching. Practical teaching is mainly based on confirmatory experiments, and practical courses are set up separately; thus, the progress cannot be synchronized with the theoretical content, resulting in the difficulty to digest knowledge and improve skills. Third, with the traditional teaching organization model and a limited teaching time, the opportunities for the integration of cutting-edge knowledge and advanced technology in related disciplines into teaching are extremely limited. All these factors restrict the teaching effect of the course as well as the level and benefit of talent training ${ }^{[2,5]}$.

\section{Analysis of works}

Based on the OBE concept, the output goal orientation of teaching will be an important navigation mark to guide the construction of the course. In the teaching reform of electronic technology courses, the focus is on the skills that can be learned, qualities that can be improved, and the support that can be provided for students' future professional learning and career development through scientific design and teaching.

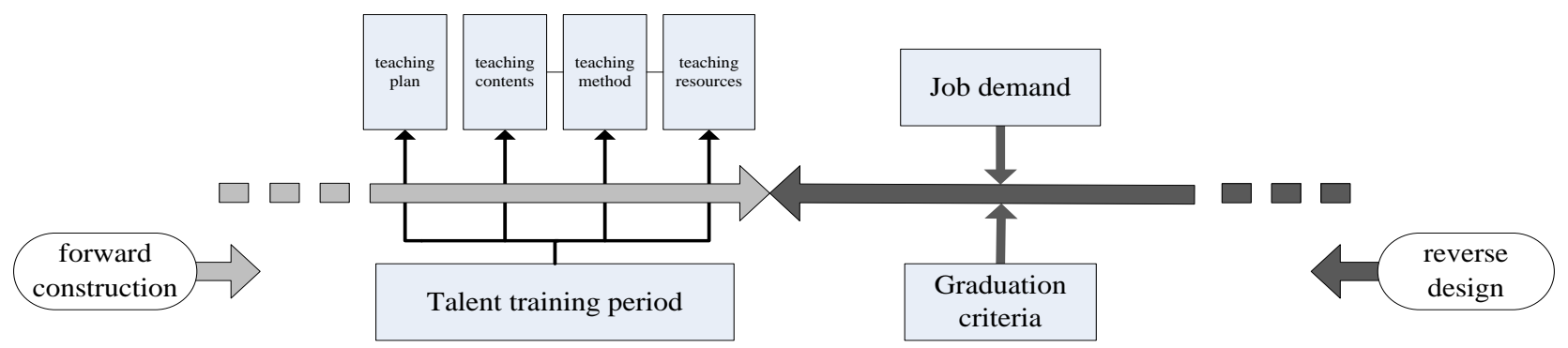

Figure 1. Design idea of course reform in higher vocational colleges based on OBE

In regard to this, the design strategy of "reverse design and forward construction" is adopted. "Reverse design" is a comprehensive consideration from multiple dimensions by investigating the ability requirements of electronic information jobs, referring to the certification standards of engineering education, and analyzing the learning needs of follow-up professional courses as well as students' graduation standards so as to form design ideas for electronic technology courses in higher vocational colleges and build a skill 
objective model around the aspects of basic knowledge and skills, engineering technology application, professional ability development, team cooperation, as well as innovation. "Forward construction" refers to the teaching plan, contents, methods, and means, in addition to the teaching effect evaluation and related resource construction of the course. It focuses on the achievement of the course goal and aggregates from bottom to top in order to form a strong support for the talent training goal and the construction of a quality course. The design idea of course reform in higher vocational colleges based on the OBE concept is shown in Figure 1.

\section{Construction of an ability objective model for electronic technology courses in higher vocational colleges}

The talent training goal of higher vocational colleges is to cultivate applied and skilled talents, which is based on the professional competency and sustainable development of talents. Electronic technology courses should focus on this goal and position their core function to consolidate students' professional basic ability, support professional learning needs, and promote the development of professional ability.

Therefore, the goal of the course should focus on four levels. The first level involves professional basic knowledge and skills. This refers to the pre-requirement of basic electrical and electronic skills that students should have before engaging in the field of electronic information as electronic information majors, which plays a basic supporting role in subsequent skill development. The second is the engineering application ability, which focuses on the ability of students to flexibly use the knowledge and skills of electronic technology to support subsequent professional learning, as well as the ability to apply electronic technology in engineering technology research and task development of their own specialty. The third is the ability of career development, which mainly refers to the learning and practical ability required by students to engage in future professional work. In other words, the ability of higher vocational talents to meet job requirements, deal with changes, and personal sustainable development, which is the impetus for long-term development. Fourth, the ability of collaboration and innovation, which focuses on the ability to integrate teamwork, trust, collaboration, sharing, mutual assistance, and support in the process of learning and working in order to promote the innovative development of individuals and careers as well as to make upward breakthroughs. Therefore, by comprehensively analyzing the social vocational needs, professional career standards, student graduation standards, and professional learning needs, the ability objective model for electronic technology courses in higher vocational colleges is established as shown in Figure 2.

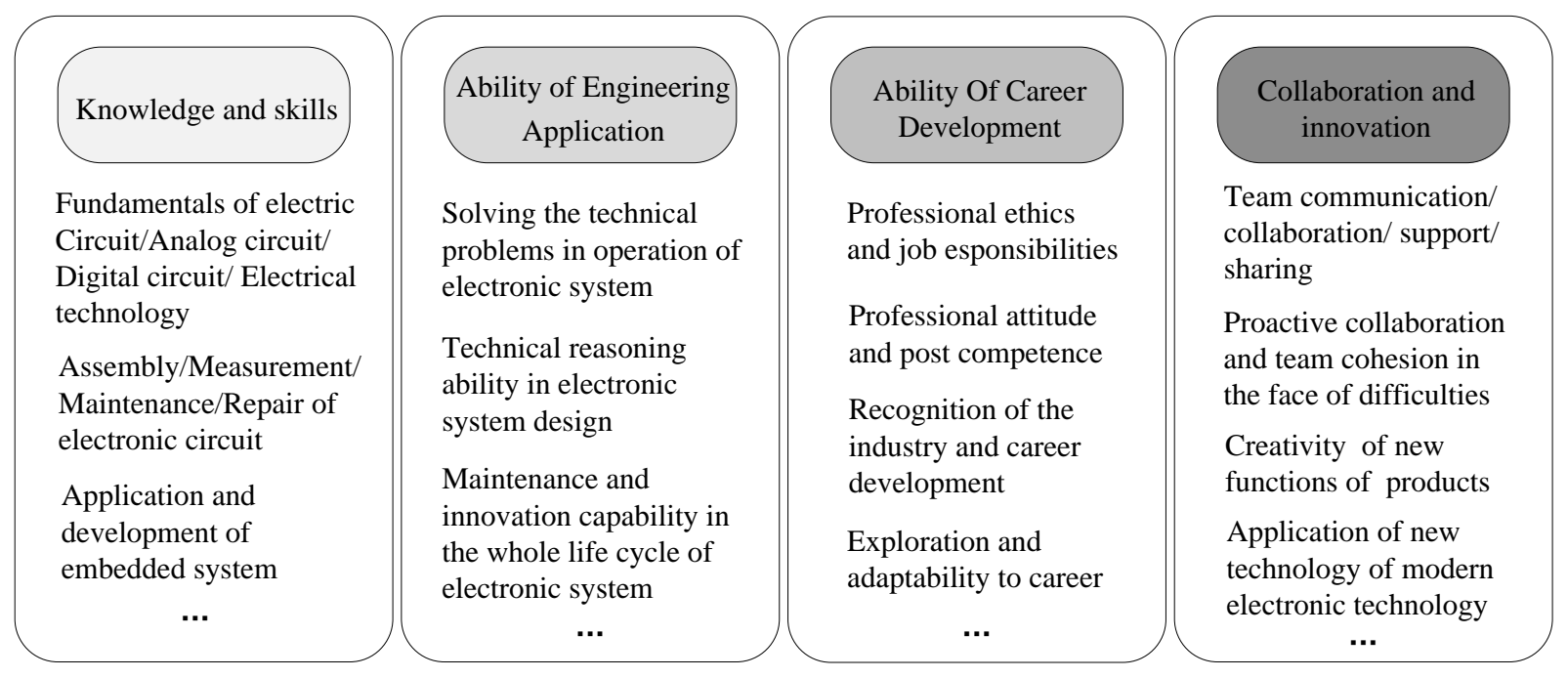

Figure 2. Ability objective model for electronic technology courses in higher vocational colleges 


\section{Electronic technology course construction in higher vocational colleges based on $\mathrm{OBE}$}

\subsection{Construction of course group based on learning achievement}

The mapping between ability objectives and course system is the core of the operability and concretization of OBE's learning output orientation. The course ability objective model is referred to and the learning results are used as the orientation to optimize and reorganize the course group. In consideration of various factors, the constraints of the traditional course system have been expounded and the electronic technology course system has been creatively reshaped. The new course system takes the whole process of a typical electronic system from signal acquisition/input, conversion/processing, control/execution to signal driving/output as the core logic line and constructs an electronic technology course group in higher vocational colleges, which includes "basic module + application module + practical training module + expansion module."

The basic module selects the basic concepts and basic principles of electrotechnics, circuit foundation, analog circuit, digital circuit, and other related courses. The goal is to enable students to establish basic concepts of electronic technology from understanding the basic components, familiarizing with basic electrical parameters, and mastering basic methods of circuit analysis. Guided by the workflow of a typical electronic system, the application module extracts corresponding electronic technical knowledge and skills according to the principle and application of each functional unit in the electronic system and carries out modular grouping of the content. The goal is to help students establish an all-round and systematic understanding of the functional principle, working mode, and circuit structure of a typical electronic system. In addition, students can cultivate the application ability of electronic technology, which lays a good foundation for future professional learning and competency in practice. The practical training module focuses on project-based and engineering practical training. It designs teaching contents around engineering links, such as electronic product design, assembly, commissioning, and maintenance. Its goal is to enhance students' autonomous learning ability and practical problem-solving ability in addition to cultivate their scientific way of thinking and sense of teamwork in order to improve their professional skills for career development. The expansion module mainly considers adding cutting-edge knowledge topics, pushing massive open online courses (MOOCs) or online micro courses resources, as well as arranging electronic workshop innovation activities and electronic design competition training so as to further enrich the connotation and extension of the course, expand students' scientific vision, and help develop a comprehensive quality.

\subsection{Construction of teaching content characterized by project-based structure}

In the selection of teaching contents, a full consideration is given to the needs of professional and career development. The teaching contents are optimized with an eye to engineering application. Firstly, aiming at the basic concepts, theorems, and basic operation skills of electronic technology, several tasks which are close to practical application are designed to guide the contents. By integrating knowledge points and skill points, the basic layer content of the course is formed by multi-point aggregation in order to build a bridge from basic knowledge and skills to practical circuit application to support the needs of the students in the field of electronic technology. Secondly, the application layer content of the course is organized with the workflow of the typical electronic system as the logical line. The specific method is to refer to the circuit functional units, such as "signal acquisition/acquisition, signal conversion/processing, signal execution/control, and power supply/monitoring"; then, integrating and generating corresponding functional circuit examples according to the modular design idea, such as $12 \mathrm{~V}$ DC regulated power supply, audible and visual anti-theft alarm, digital timing circuit, etc. The purpose of this is to effectively connect the teaching content with the practical application of electronic technology as well as to enhance the 
pertinence and effectiveness of teaching. On the basis of the previous two content levels, the depth and foresight of the teaching content should be fully tapped, the key and difficult points as well as the development of new technologies in the field should be highlighted, engineering training projects with different difficulty coefficients according to the idea of engineering should be designed and formed, and comprehensive practical teaching related to electronic system design, maintenance, and process manufacturing should be carried out. The purpose is to create opportunities for students to innovate in engineering practice. In the design of teaching content at this level, it is necessary to fully consider how to stimulate students' subjective initiative as well as to encourage open thinking and teamwork so as to lay a good foundation for consolidating their professional basic ability and enhancing professional competence.

\subsection{Application of a teaching organization model with ability training as the core}

Based on the engineering teaching concept, different teaching organization forms are designed according to different teaching contents. The goal is to further improve students' ability and thinking consciousness to integrate theory into practice, scientifically carry out engineering practice, and improve their engineering literacy as well as professional ability through the interactive resonance between teaching and learning.

For the content of the basic layer, both the theoretical content and practical content are implemented in parallel. The connection points between the two are strictly controlled to realize the interconnection of theory and practice in order for students to have good understanding, memory, and intuitive impression. For the content of the application layer, the teaching concept of practice-oriented and task-driven is adopted. It is characterized by taking the circuit function module as the subject, students as the main body, and teachers as the guide. In the teaching process, students' subject consciousness and learning motivation are stimulated through the implementation of functional analysis, problem-solving, knowledge learning, task practice, and other links. The purpose is to strengthen students' understanding and mastery of knowledge as well as skills in addition to cultivating their application ability of electronic technology. For the content of engineering training project, the teaching process involves the actual engineering project management process. Students would be required to independently establish a project team of appropriate scale according to the difficulty of the project. Teachers would then play the role of an engineering technology supervisor to evaluate and guide the project scheme proposed by students. The project team can then independently complete the whole process of project design and implementation. Through engineering project training, the goal is to promote the cultivation of students' innovation ability, engineering practice literacy, and teamwork consciousness, as well as to improve students' comprehensive ability for professional learning and career development.

\subsection{Construction of teaching staffs and teaching resources}

In order to fully support the goal of course construction, it is necessary to continuously improve the supporting construction, such as teaching materials and handouts, teaching conditions and information resources, as well as the overall ability of teachers. In regard to that, teaching contents are designed according to the above modular and project-based principles, and the corresponding teaching materials as well as handouts are compiled. In the current educational information and intelligent environment, the construction and sharing of network resources should be actively promoted along with building course websites, recording micro courses and MOOCs, as well as carrying out learning exchanges, testing, and Q\&A (questions-and-answers) sessions with the help of the network so as to create rich online and offline course resources. It has been suggested that the construction of smart classrooms, smart laboratories, and other environments should be vigorously carried out; mainstream experimental platforms or self-developed teaching platforms in the industry should be introduced; advanced virtual simulation environment should 
be configured; first-class software and hardware conditions in combination with teaching practices should be developed.

In terms of training for teachers, schools should formulate scientific and effective measures from the aspects of policy guidance, incentive measures, training plan, and qualification recognition. On the other hand, teachers should make continuous efforts in terms of their academic qualifications, professional quality, and teaching ability so as to form good interactions between both parties, create a proper environment for their growth, as well as improve and accumulate excellent teachers. The purpose of continuous improvement and optimization of these elements is to provide a strong support for improving students' professional learning ability and professional employability.

\section{Conclusion}

In order to meet the practical needs of higher vocational colleges to improve the construction level of electronic information specialty and enhance students' professional competence, an all-rounded course construction has been carried out in the reform of electronic technology courses with reference to the OBE engineering education concept and the demand for professional learning as well as career development. In regard to the teaching practice in recent years, the ideas and methods for the curriculum construction of electronic technology courses based on OBE can effectively improve students' professional learning and competency in addition to provide effective ideas and methods for the curriculum construction of higher vocational colleges in the new era.

\section{Disclosure statement}

The authors declare that there is no conflict of interest.

\section{References}

[1] Liao JH, Li LX, Zhang CF, et al., 2017, Research-Teaching Reform of the Electronic Process Course Based on OBE. Experiment Science and Technology, 15(4): 72-76.

[2] Chen YS, Lee TR, Wu ZK, et al., 2017, Research and Design of the Educational Model of Engineering Specialty in Higher Vocational Education from the Perspective of OBE. Guangdong Industry Polytechnic, 16(3): 54-57.

[3] Zeng SM, Chen A, Jiang LL, et al., 2019, Experiment Teaching Reform of Step-by-step Analog Electronic Technology Based on OBE. China Modern Education Equipment, 327: 66-68.

[4] Li HJ, 2019, Reform and Practice of Teaching Methods of Electrical Technology and Electronic Technology. Products and Circulation of Computer, 7: 252-255.

[5] Wei J, Li DJ, Guo XJ, 2019, Exploration of Practical Teaching Reform in Colleges under the Background of Emerging Engineering Education. Internet of Things Technology, 2: 118-120. 